\section{Commentary: Maybe it is better to be a lefty}

\author{
Michael D. Taylor, MD, PhD
}

The Fontan operation is often the final planned procedure in the staged palliation of functional single-ventricle heart disease, but its effect on ventricular function remains poorly understood. The fascinating study in the current issue by Shiraga and colleagues ${ }^{1}$ attempts to answer 2 questions about single ventricles and the Fontan: (1) How does the Fontan operation affect ventricular function and (2) are there differences between single right (SRV) and single left ventricular (SLV) function? To examine these questions, the authors measured myocardial strain by feature tracking analysis of cardiac magnetic resonance images pre- and post-Fontan in a group of single-ventricle patients.

The primary finding was a small decrease in strain after the Fontan for the SRV. This novel finding raises interesting questions about the palliation, single-ventricle physiology, and measurement techniques. It suggests that the Fontan operation itself results in reduced myocardial deformation, albeit one that is too small to change volumetric parameters. The mechanism for this effect is unknown. It could be the deleterious effects of cardiopulmonary bypass, hemodynamic perturbation, or even neurohormonal changes. Likely, it is a combination of factors, some of which we cannot measure.

Whether the observed reductions in certain strain directions are important is unknown. The mean strain magnitude changes were small, and we do not know the thresholds for clinically important changes. Only the radial and circumferential components decreased after the Fontan. Longitudinal shortening did not change. We know that longitudinal shortening is important in right ventricular deformation based on its fiber orientation, so its maintenance may be compensatory. Hopefully, slightly longer longitudinal

\footnotetext{
From The Heart Institute - Cardiology, Cincinnati Children's Hospital Medical Center, Cincinnati, Ohio.

Disclosures: The author reported no conflicts of interest.

The Journal policy requires editors and reviewers to disclose conflicts of interest and to decline handling or reviewing manuscripts for which they may have a conflict of interest. The editors and reviewers of this article have no conflicts of interest.

Received for publication March 1, 2021; revisions received March 1, 2021; accepted for publication March 2, 2021; available ahead of print March 5, 2021.

Address for reprints: Michael D. Taylor, MD, PhD, The Heart Institute - Cardiology, Cincinnati Children's Hospital Medical Center, 3333 Burnet Ave, Cincinnati, OH 45229 (E-mail: Michael.Taylor1@ @chmc.org).

J Thorac Cardiovasc Surg 2021;162:1823-4

$0022-5223 / \$ 36.00$

Copyright (c) 2021 by The American Association for Thoracic Surgery

https://doi.org/10.1016/j.jtcvs.2021.03.007
}

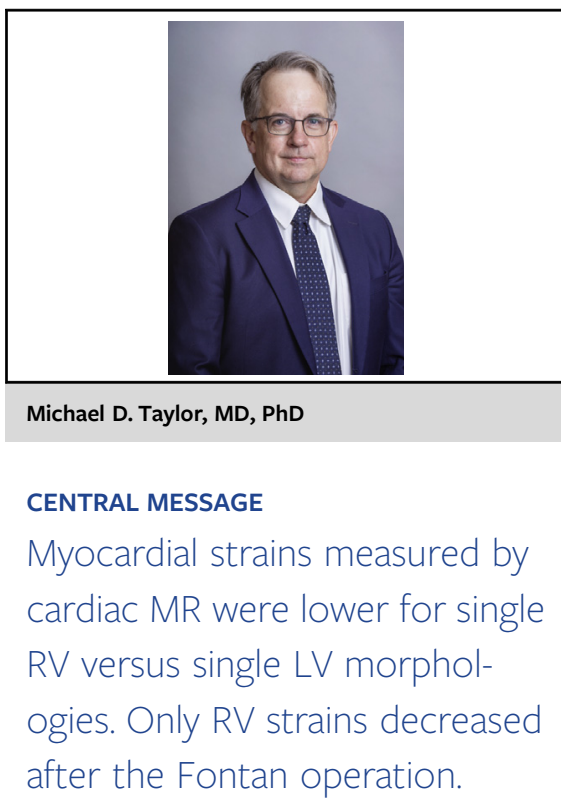

follow-up of this subset of patients will inform as to the importance of these deformation changes.

The authors also found a difference in strain components between SRV and SLV before and after the Fontan whereas the ejection fractions were unchanged. This suggests that the SRV is less vigorous going to the Fontan and that the SRV reacts less favorably to the Fontan operation. This finding supports the concept of the SRV being more fragile during single-ventricle palliation, as evidenced by several outcome studies., ${ }^{2,3}$ However, it is also possible the observed strain differences are due to inherent problems with using 2-dimensional strain directions for both the SLV and SRV. Using the standard radial, circumferential, and longitudinal primary strain vector components is useful for measuring deformation of the prolate ellipsoid shaped LV. This framework is not optimized for the irregularly shaped RV and may not capture accurately its 3-dimensional (3D) motion. Data from full 3D strain analysis show the inability of 2-dimensional strain to capture the motion. ${ }^{4}$ Hopefully, advances in 3D cine magnetic resonance imaging acquisition and analysis will provide these data. Until then, we should interpret carefully comparisons of 2-dimensional strain components between the SRV and SLV.

This study shows an interesting decrease in deformation parameters after Fontan for the SRV but not the SLV. Even with the difficulties in comparing deformation parameters between morphologies, the study supports early and aggressive attention to the right ventricle during single-ventricle palliation. 


\section{References}

1. Shiraga K, Ozcelik N, Harris MA, Whitehead KK, Biko DM, Partington SL, et al. Imposition of Fontan physiology: effects on strain and global measures of ventricular function. J Thorac Cardiovasc Surg. 2021;162:1813-23.e3.

2. Stephens EH, Talwar AA, Devlin PJ, ltayeb O, Mongé MC, Tsao S, et al. 24-year results of non-fenestrated extracardiac Fontan including Fontan conversions. Ann Thorac Surg. August 11, 2020 [Epub ahead of print].
3. Mery CM, León LED, Trujillo-Diaz D, Ocampo EC, Dickerson HA, Zhu H, et al. Contemporary outcomes of the Fontan operation: a large single-institution cohort. Ann Thorac Surg. 2019;108:1439-46.

4. Moceri P, Duchateau N, Gillon S, Jaunay L, Baudouy D, Squara F, et al. Threedimensional right ventricular shape and strain in congenital heart disease patients with right ventricular chronic volume loading. Eur Heart J Cardiovasc Imaging. August 5, 2020;jeaa189. 